Article

\title{
Grain Refinement Mechanism of the As-Cast and As-Extruded Mg-14Li Alloys with Al or Sn Addition
}

\author{
Ying Zeng ${ }^{1,2}$, Bin Jiang ${ }^{2,3, *}$, Ruihong $\mathrm{Li}^{2}$, Hengmei Yin ${ }^{2}$ and Salih Al-Ezzi ${ }^{1}$ \\ 1 Key Laboratory of Advanced Technologies of Materials, Ministry of Education, School of Material Science \\ and Engineering, Southwest Jiaotong University, Chengdu 610031, China; \\ zengyingying1988@163.com (Y.Z.); salihlink@yahoo.com (S.A.-E.) \\ 2 State Key Laboratory of Mechanical Transmissions, College of Materials Science and Engineering, \\ Chongqing University, Chongqing 400044, China; liruihong1019@163.com (R.L.); \\ Yinhengmei1986@126.com (H.Y.) \\ 3 Chongqing Research Center for Advanced Materials, Chongqing Academy of Science and Technology, \\ Chongqing 401123, China \\ * Correspondence: jiangbinrong@cqu.edu.cn; Tel.: +86-135-9419-0166
}

Academic Editors: Ali Ramazani and Veera Sundararaghavan

Received: 13 April 2017; Accepted: 9 May 2017; Published: 13 May 2017

\begin{abstract}
The microstructures of the as-cast and as-extruded Mg-14 wt. \% Li-1 wt. \% Al (LA141) and Mg-14 wt. \% Li-2 wt. \% Sn (LT142) were observed by optical and scanning electron microscope (SEM), X-ray diffraction (XRD) and differential scanning calorimetry (DSC). The effects of Al and $\mathrm{Sn}$ on the grain refinement on the $\mathrm{Mg}-14 \mathrm{Li}$ alloy were investigated. In addition, the mechanism of grain refinement on the as-cast and as-extruded alloys was discussed from the view of the solute effect and heterogeneous nucleation effect via edge-to-edge matching model. The results showed that the average grain sizes of the as-cast LA141 and LT142 alloys were similar due to the close solute effect of $1.1 \mathrm{wt}$. \% Al and $1.8 \mathrm{wt}$. \% Sn, while, in the as-extruded alloys, the average grain size of LT142 was over two times finer than that of LA141. This was attributed to the reason that $\mathrm{Li}_{2} \mathrm{MgSn}$ particles can serve as heterogeneous nucleation sites for the $\beta$-Li matrix during the process of dynamic recrystallization (DRX), but $\mathrm{LiMgAl}_{2}$ cannot serve the same way. Therefore, $\mathrm{Sn}$ can act as a more effective grain refiner for the $\mathrm{Mg}-14 \mathrm{Li}$ alloy compared to $\mathrm{Al}$.
\end{abstract}

Keywords: magnesium-lithium (Mg-Li) alloy; grain refinement; heterogeneous nucleation; edge-to-edge matching model

\section{Introduction}

Conventional Mg alloys, such as AZ31, AZ61, and ZK60, exhibited poor formability at room temperatures, which was caused by the limited number of active slip systems in the hexagonal close-packed (HCP) structures [1,2]. Compared to the Mg alloys with an HCP structure, the alloys with a body-centered cubic (BCC) structure have more active slip planes and slip directions [3].

The lithium $(\mathrm{Li})$ additions to $\mathrm{Mg}$ alloys cause the transformation of the crystal structure. After $\mathrm{Li}$ contents increase to $5.5 \mathrm{wt}$. \%, a $\beta$-Li phase with BCC structure appear. Then, with the increase of the $\mathrm{Li}$ contents, the proportion of the $\beta$ - $\mathrm{Li}$ phase in $\mathrm{Mg}-\mathrm{Li}$ alloy increases. When $\mathrm{Li}$ content is beyond $10.5 \mathrm{wt}$. $\%$, the phase composition in the $\mathrm{Mg}-\mathrm{Li}$ alloy will be the single $\beta$-Li phase $[4,5]$. BCC structure possesses much more available slip systems, and the cubic Mg alloys are less prone to develop disadvantageous deformed textures [6]. Therefore, the $\mathrm{Mg}-\mathrm{Li}$ alloys with the $\mathrm{Li}$ contents beyond $10.5 \mathrm{wt}$. \% exhibited excellent formability and ductility or even super-plasticity [7-9]. However, the binary $\mathrm{Mg}-\mathrm{Li}$ alloys cannot meet the industrial strength requirements [10]. The addition of alloying 
elements to $\mathrm{Mg}-\mathrm{Li}$ alloys was considered as an effective method to improve the strength of $\mathrm{Mg}-\mathrm{Li}$ alloys due to its easy operation and cost-saving [11-13].

In recent years, the $\mathrm{Mg}-14 \mathrm{Li}-1 \mathrm{Al}$ (LA141) alloy was developed as a commercial alloy due to its low density and good plasticity [14-16]. The addition of Al could refine the grains of the Mg-Li alloys. The $\mathrm{Li}_{2} \mathrm{MgAl}$ particles, precipitating from the LA141 molten alloy, could strengthen the $\beta$-phase matrix in the $\mathrm{Mg}-\mathrm{Li}-\mathrm{Al}$ system [17]. However, $\mathrm{Li}_{2} \mathrm{MgAl}$ was metastable and would be decomposed at $66^{\circ} \mathrm{C}$ or even at room temperature [14]. Therefore, ideal candidates need to be explored for the improvement of the Mg-14Li alloys.

Many researchers have found that $\mathrm{Sn}$ was a favorable element for addition to $\mathrm{Mg}-\mathrm{Li}$ alloys. With $\mathrm{Sn}$ addition to $\mathrm{Mg}-\mathrm{Li}$ alloys, the lamellar $\mathrm{Mg}_{2} \mathrm{Sn}$ presented in the dendritic crystal boundary and a tiny granular $\mathrm{Mg}_{2} \mathrm{Sn}$ existed inside the grains, resulting in the significant refinement of the secondary dendrite arm spacing of the $\alpha-\mathrm{Mg}$ phase [18-20]. Furthermore, Zeng et al. [21] and Yin et al. [22] have studied the effect of $\mathrm{Sn}$ on the grain refinement of $\mathrm{Mg}-\mathrm{Li}$ alloys. It was found that the precipitates $\mathrm{Mg}_{2} \mathrm{Sn}$ or $\mathrm{Li}_{2} \mathrm{MgSn}$ could act as heterogeneous nucleation sites for the $\mathrm{Mg}$ matrix in the process of solidification, leading to a grain refinement in $\mathrm{Mg}-\mathrm{Li}$ alloys. Nevertheless, the specific refinement mechanism of Sn on Mg-14Li alloys, especially on the as-extruded Mg-14Li alloys, was rarely covered in those studies.

In this work, $\mathrm{Al}$ and $\mathrm{Sn}$ were added into the $\mathrm{Mg}-14 \mathrm{Li}$ alloy followed by extrusion to investigate the effect of $\mathrm{Al}$ and $\mathrm{Sn}$ addition on the grain refinement of the as-cast and as-extruded $\mathrm{Mg}-14 \mathrm{Li}$ alloy. As part of the rssearch on Mg-Li based alloys in our study [15,23], this paper aims to explore the different grain refinement effect, which was raised by different intermetallics $\left(\mathrm{Li}_{2} \mathrm{MgSn}\right.$ and $\left.\mathrm{LiMgAl}_{2}\right)$ in $\beta$-based $\mathrm{Mg}-\mathrm{Li}$ alloys. Meanwhile, the distinctions of grain refinement mechanism between the as-cast and as-extruded alloys were also discussed.

\section{Materials and Methods}

The raw materials used in preparing the $\mathrm{Mg}-14 \mathrm{wt}$ \% $\% \mathrm{Li}-1$ wt. \% $\mathrm{Al}$ (LA141) and Mg-14 wt. \% Li-2 wt. \% Sn (LT142) alloys were commercial pure magnesium (99.9 wt. \%), pure lithium (99.9 wt. \%), pure aluminum (99.9 wt. \%), and high pure tin (99.99 wt. \%). For LA141 alloy, before being melting, the pure $\mathrm{Mg}$, pure $\mathrm{Li}$ and pure $\mathrm{Al}$ metals were put into a stainless steel crucible $(90 \mathrm{~mm}$ in diameter, $250 \mathrm{~mm}$ in height, Jinfa Stainless Steel, Chongqing, China), placing in an induction furnace (Yuantong Power Apparatus Ltd., Jinzhou, China). Then, the materials were heated to $700{ }^{\circ} \mathrm{C}$ under a protective atmosphere of pure argon. After isothermal holding for $10 \mathrm{~min}$, the crucible with the melt was cooled in the furnace under the argon atmosphere, and an LA141 cast ingot was obtained. The LT142 alloy was prepared under the same conditions. Before the extrusion, the cylindrical cast ingots were homogenized at $250^{\circ} \mathrm{C}$ for $8 \mathrm{~h}$ with air-cooling, followed by milling to remove the oxide layer and casting defects on the surface. Then, the ingots were extruded at $250{ }^{\circ} \mathrm{C}$ with an extrusion ratio of 28 and an extrusion speed of $20 \mathrm{~mm} \cdot \mathrm{s}^{-1}$. Finally, the extruded bars with a diameter of $16 \mathrm{~mm}$ were obtained. In our whole study, other alloys with different $\mathrm{Al}$ and Sn contents were also prepared. However, in this study, two specific alloys of LA141 and LT142 were chosen for discussion due to their meaningful observed results.

The compositions of the studied alloys were measured by inductively coupled plasma atomic emission spectroscopy (ICP-AES), and the measured compositions of the LA141 and LT142 alloys were $\mathrm{Mg}-14.3 \mathrm{Li}-1.1 \mathrm{Al}$ and $\mathrm{Mg}-14.4 \mathrm{Li}-1.8 \mathrm{Sn}$, respectively. All the samples used in the following characterization were cut from the center of the ingots or extruded bars. The optical microscopy and scanning electron microscopy (SEM, TESCAN VEGA 3LMH, BrNo, Czech Republic) were applied to characterize the microstructures after etching by picric acid solution ( $5 \mathrm{~g}$ picric, $10 \mathrm{~mL}$ acetic acid, $100 \mathrm{~mL}$ ethanol and $10 \mathrm{~mL}$ distilled water). The differential scanning calorimetry (DSC) of NETZSCH STA 449C system (NETZSCH, Selb, Germany) was used to analyze the solidification behavior of the experimental alloys. The as-cast samples for DSC measurement were heated from 20 to $700{ }^{\circ} \mathrm{C}$ at a rate of $5{ }^{\circ} \mathrm{C} \cdot \mathrm{min}^{-1}$. The grain size was measured by the linear intercept method at the center of 
the transverse sections. The phases of the alloys were identified by X-ray diffraction (XRD, Rigaku

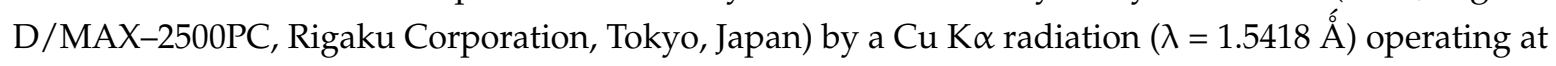
the speed of $4^{\circ} / \mathrm{min}$ and a $2 \theta$ ranging from $10^{\circ}$ to $90^{\circ}$.

\section{Results}

The average grain size of the typical as-cast Mg-14Li alloy was $784 \mu \mathrm{m}$ [24]. After adding $\mathrm{Al}$ or $\mathrm{Sn}$ to the $\mathrm{Mg}-14 \mathrm{Li}$ alloy, as shown in Figure 1a,b, the grain size decreases to 591 and $608 \mu \mathrm{m}$, respectively. The similar decrease rate of grain sizes in the LA141 and LT142 alloys implies that the effect of $1.1 \mathrm{wt}$. \% $\mathrm{Al}$ and $1.8 \mathrm{wt}$. \% $\mathrm{Sn}$ on the grain refinement in the as-cast $\mathrm{Mg}-14 \mathrm{Li}$ might be similar. However, after extrusion, the grains of the as-extruded LT142 alloy appear to be much finer than those of the LA141 alloy. As shown in Figure 1c,d, the average grain sizes of the as-extruded LA141 and LT142 alloys are 64.2 and $29.8 \mu \mathrm{m}$, respectively.

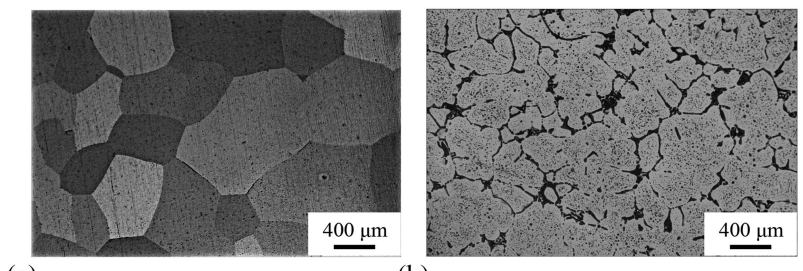

(a)

(b)
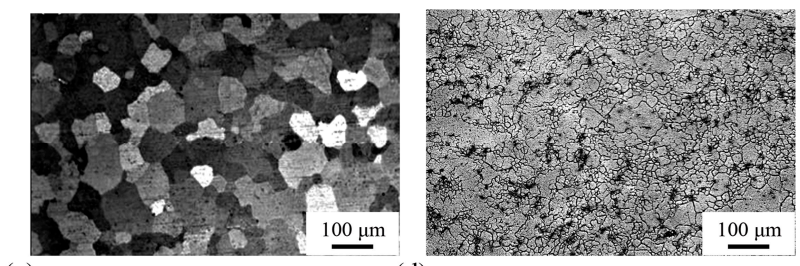

(c)

(d)

Figure 1. Microstructure of the as-cast: (a) LA141; and (b) LT142 alloys. Microstructure of the as-extruded: (c) LA141; and (d) LT142 alloys.

According to the binary Mg-Li phase diagram, the microstructures of Mg-14 wt. \% Li alloy at room temperature mainly consists of $\beta$-Li [25]. Figure 2 demonstrates the XRD patterns taken from the as-cast alloys. It is shown that $\mathrm{Li}_{2} \mathrm{MgSn}$ or $\mathrm{LiMgAl}_{2}$ phases are formed with the addition of $\mathrm{Al}$ or $\mathrm{Sn}$. It was reported that $\mathrm{Li}_{2} \mathrm{MgAl}$ precipitated from the matrix during the solidification process in the LA141 alloy [26]. However, in our study, the $\mathrm{LiMgAl}_{2}$ peaks were indexed in LA141 alloy. This can be attributed to the reason that $\mathrm{Li}_{2} \mathrm{MgAl}$ phase was metastable and easy to resolve to $\mathrm{Li}_{2} \mathrm{MgAl}$ or $\mathrm{AlLi}$ phases [14]. Moreover, Sn can also be found in the LT142 alloy due to its low solubility in $\beta-\mathrm{Li}$.

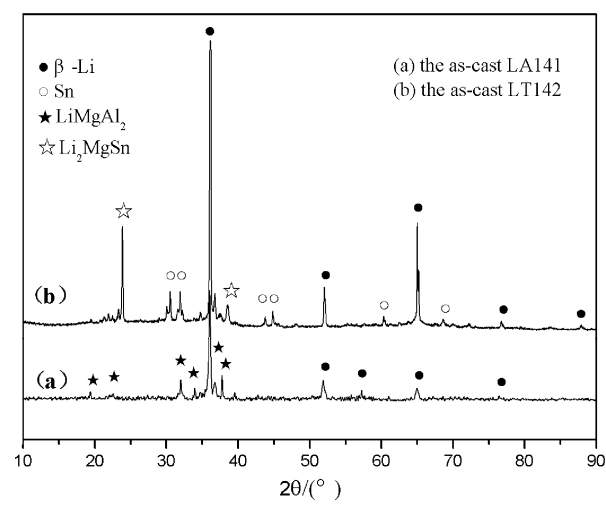

Figure 2. The X-ray diffraction (XRD) patterns of the as-cast: (a) LA141; and (b) LT142 alloys. 
Figure 3 shows the SEM images of the as-cast and as-extruded alloys. The phase compositions were analyzed with EDS and marked in the SEM images. As shown in Figure 3a, in the as-cast LA141 alloy, the granular $\mathrm{LiMgAl}_{2}$ phases are distributed in the matrix, while, in the as-cast LT142 alloy, as depicted in Figure 3b, the lamellar $\mathrm{Li}_{2} \mathrm{MgSn}$ phases are mainly located at the grain boundaries. After extrusion, as demonstrated in Figure 3c,d, intermetallics both in the LA141 or LT142 alloys are well distributed in the matrix with a granular structure. It was reported that the wetting transitions of second phase particles with the grain boundaries contributed to the morphologic and distributed transitions $[27,28]$. Therefore, it can be speculated that the different morphology and distribution of precipitates in LA141 and LT142 alloys, as shown in Figure 3, was caused by the different wetting effect of $\mathrm{LiMgAl}_{2}$ and $\mathrm{Li}_{2} \mathrm{MgSn}$ with the grain boundaries.

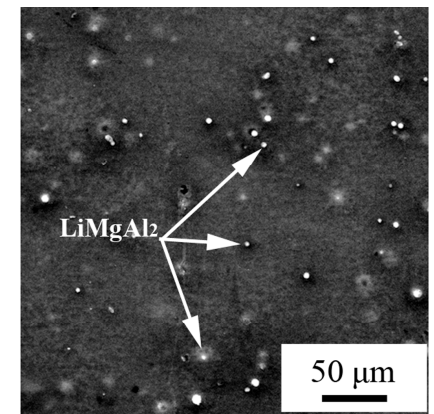

(a)

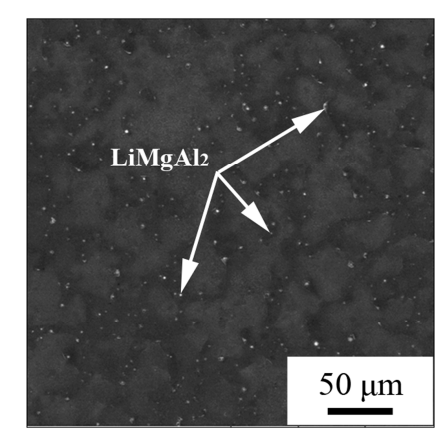

(c)

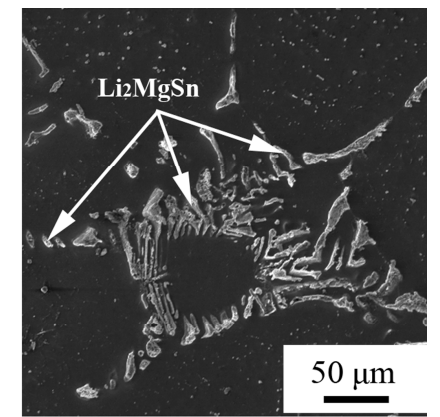

(b)

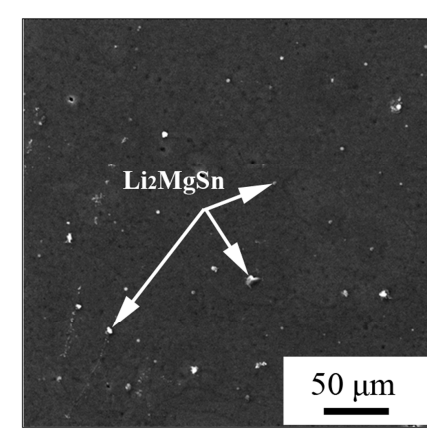

(d)

Figure 3. Scanning electron microscopy (SEM) images of the as-cast: (a) LA141; and (b) LT142 alloys. SEM images of the as-extruded: (c) LA141; and (d) LT142 alloys.

\section{Discussion}

Easton et al. [29,30] and Fu et al. [31] studied the grain refinement of the alloying in metallic materials and found that the grain refinement was mainly related to two factors. One is the segregation power of the solute elements, defining as the solute effect, and the other is the heterogeneous nucleation effect.

\subsection{Mechanism of Grain Refinement in the As-Cast Alloys}

To figure out which factor dominates the refinement in the as-cast alloys, the solidification route should be analyzed at first. DSC curves are obtained to reflect the formation temperature of each phase in the solidification process. As shown in Figure 4a, at the beginning of the solidification of the LA141 alloy, $\beta$-Li phase forms preferentially from the melted alloy at a temperature of $600{ }^{\circ} \mathrm{C}$. The phase analysis results, as shown in Figures 2 and 3, indicated that $\mathrm{MgLiAl}_{2}$ existed in the LA141 alloy. Thus, after the formation of the $\beta$-Li matrix, $\mathrm{MgLiAl}_{2}$ phase precipitates at $385^{\circ} \mathrm{C}$. Then, the melt continues cooling until complete solidification. Therefore, the solidification path of the LA141 alloy is depicted as follows: Liquid $\rightarrow\left(600^{\circ} \mathrm{C}\right) \beta$-Li phase $\rightarrow\left(385^{\circ} \mathrm{C}\right) \mathrm{LiMgAl}_{2}$. 


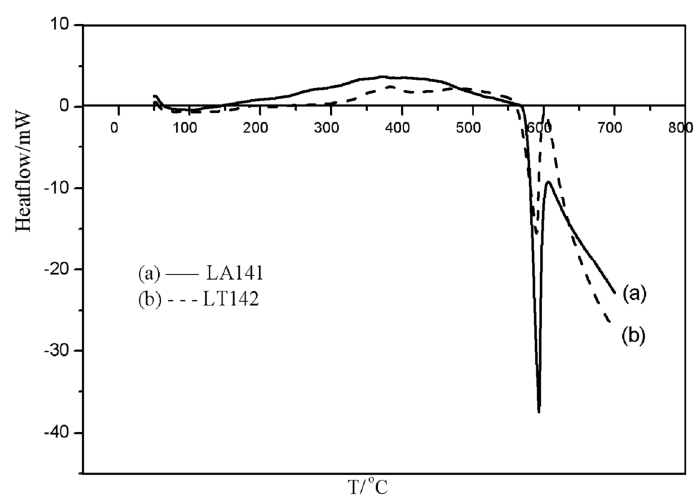

Figure 4. Differential scanning calorimetry (DSC) curves of the as-cast: (a) LA141; and (b) LT142 alloys.

Similarly, the solidification path of the LT142 alloy is determined: Liquid $\rightarrow\left(600^{\circ} \mathrm{C}\right) \beta$-Li phase $\rightarrow\left(362{ }^{\circ} \mathrm{C}\right) \mathrm{Li}_{2} \mathrm{MgSn}$. The solidification process of the LA141 and LT142 alloys indicates that the formation temperature of the intermetallics $\left(\mathrm{LiMgAl}_{2}\right.$ and $\left.\mathrm{Li}_{2} \mathrm{MgSn}\right)$ is lower than that of the $\beta$ - $\mathrm{Li}$ matrix. It means that these intermetallics cannot be the heterogeneous nucleation sites for the matrix. Thus, the mechanism of grain refinement in the as-cast alloys might be dominated by the solute effect.

Greer et al. [32,33] suggested that the final grain size and phase structure was determined by the nucleation and growth conditions prevailing during phase transformation. The solute effect raised by alloying elements was often quantified by the growth restriction factor $(G R F)$ and is defined as [29,30]:

$$
G R F=\sum_{i} m_{i} c_{o, i}\left(k_{i}-1\right)
$$

where $m_{i}$ denotes the liquid gradient of the binary phase diagram, $c_{o, i}$ is the solid original content, and $k_{i}$ is the solute distribution coefficient [3]. A solute with a higher value of GRF is expected to have a stronger grain growth restriction impact.

Combining Equation (1) with the $\mathrm{Li}-\mathrm{Al}(\mathrm{Sn})$ phase diagram [25], the per unit GRF values of $\mathrm{Al}$ and $\mathrm{Sn}$ in Li can be calculated, and they are 6.2 and 4.3, respectively. It can be seen that the contents of $\mathrm{Sn}$ is 1.5 times more than that of $\mathrm{Al}$, while the GRF value of $\mathrm{Al}$ is 1.6 times higher than that of $\mathrm{Sn}$. Therefore, the grain growth restriction impact between the $1.1 \mathrm{wt}$ \% $\mathrm{Al}$ and $1.8 \mathrm{wt}$ \% $\mathrm{Sn}$ in Li should be close, which leads to the similar grain sizes of the as-cast LA141 and LT142 alloys, as confirmed in Figure 1a,b. From the above analysis, it can be deduced that the main reason of grain refinement in the solidification process of the LA141 and LT142 alloys should be the solute effect of Al and Sn in the melted alloys.

\subsection{Mechanism of Grain Refinement in the As-Extruded Alloys}

Both the grains in the LA141 and LT142 alloys were gained refinement after extrusion, as shown in Figure 1. It was known that this refinement was due to the effect of dynamic recrystallization (DRX) during the extrusion process [34]. However, the grains in the as-extruded LT142 were two times finer than those in LA141. Classical theory about the particle stimulated nucleation suggested that particles which do not deform will produce additional strain in the surrounding matrix and thus generate a fine dense substructure suitable for nucleation, stimulating the nucleation of DRX in metal alloys [35,36]. Besides, Zhang et al. [37-39] raised an edge-to-edge matching model for the heterogeneous nucleation effect in metal alloys. It was speculated that the particles, which have a good crystallographic relationship with the matrix, are most likely to serve as the nucleation sites for the matrix in the DRX process. According to this model, the particles with a proper size and the lowest mismatch with the metal matrix tend to serve as the nucleation sites for the metal matrix during the solidification process or dynamic recrystallization. From the perspective of quantification, if the particles can act as the grain refiner for the matrix, there should be at least one pair of close-packed 
atomic rows. The close-packed atomic rows were defined as matching rows, whose interatomic spacing misfit $\left(f_{r}\right)$ is less than $10 \%$ between this pair rows. In addition, the matching rows should be contained in at least one pair of close-packed planes, defined as matching planes, with interplanar spacings ( $d$-values) showing a mismatch $\left(f_{d}\right)$ of less than $10 \%$, while the strict critical value is $6 \%$.

Therefore, the key point to understand the grain refinement mehanism of $\mathrm{Al}$ or Sn addition on the as-extruded $\mathrm{Mg}-14 \mathrm{Li}$ alloy is to identify the matching planes and matching directions of the intermetallics and the matrix. That is, in the $\mathrm{LiMgAl} 2 / \mathrm{Li}_{2} \mathrm{MgSn}$ and $\mathrm{Li}$ system, the $r$-value misfit along that direction and the $d$-value mismatch of the matching planes should be calculated firstly [30].

For the $\mathrm{LiMgAl}_{2}$ and $\mathrm{Li}$ matrix system, according to the crystallographic database and X-ray powder diffraction data [40], the crystal structure of $\mathrm{LiMgAl}_{2}$ is face-centered cubic (FCC). Its three close packed planes are the $\{660\},\{422\}$ and $\{511\}$ planes, while those of Li are the $\{110\},\{211\}$ and $\{200\}$ planes. The $f_{d}$ values between $\mathrm{LiMgAl}_{2}$ and the Li matrix can be calculated [23], and the possible values are listed in Table 1 . Through this table, it can be seen that all the $f_{d}$ values of the matching planes are beyond the critical value of $6 \%$, which means this particle is nearly impossible to be the heterogeneous nucleation site for the $\beta$-Li phase.

Table 1. Interplanar spacing mismatch $\left(f_{d}\right)(\%)$ along the possible matching planes between the intermetallics and Li matrix. Some pairs of close-packed planes are ignored because their $f_{d}$ are beyond $100 \%$.

\begin{tabular}{cccccc}
\hline Intermetallics & \multicolumn{5}{c}{ The Mismatch between the Intermetallics and Matrix (\%) } \\
\hline & $\{110\}_{\beta-L i} /$ & $\{211\}_{\beta-L i} /$ & $\{220\}_{\beta-L i} /$ & $\{110\}_{\beta-L i} /$ & $\{110\}_{\beta-L i} /$ \\
$\mathrm{LiMgAl}_{2}$ & $\{660\}_{L i M g A l_{2}}$ & $\{660\}_{L i M g A l_{2}}$ & $\{660\}_{L i M g A l_{2}}$ & $\{422\}_{L i M g A l_{2}}$ & $\{511\}_{L i M g A l_{2}}$ \\
& 6.85 & 61.54 & 31.25 & 65.73 & 56.05 \\
& $\{110\}_{\beta-L \mathrm{i}} /$ & $\{110\}_{\beta-L \mathrm{i}} /$ & $\{211\}_{\beta-L \mathrm{i}} /$ & $\{211\}_{\beta-L \mathrm{i}} /$ & $\{220\}_{\beta-L \mathrm{i}} /$ \\
$\mathrm{Li}_{2} \mathrm{MgSn}$ & $\{111\}_{L i_{2} M g S n}$ & $\{220\}_{L i_{2} M g S n}$ & $\{220\}_{L i_{2} M g S n}$ & $\{751\}_{L i_{2} M g S n}$ & $\{220\}_{L i_{2} M g S n}$ \\
& 57.66 & 3.62 & 67.13 & 45.46 & 35.80 \\
\hline
\end{tabular}

As for the $\mathrm{Li}_{2} \mathrm{MgSn}$ and $\mathrm{Li}$ matrix system, $\mathrm{Li}_{2} \mathrm{MgSn}$ possesses a BCC structure, and its close packed planes are $\{111\},\{220\}$, and $\{751\}$. Analogously, the $f_{d}$ values between $\mathrm{Li}_{2} \mathrm{MgSn}$ and the Li matrix can be obtained, and the possible matching planes of Li matrix and $\mathrm{Li}_{2} \mathrm{MgSn}$ are $\{110\}_{\beta-L i} /\{220\}_{\mathrm{Li}_{2} M g S n}$, as indicated in Table 1 . The crystallographic information for $\mathrm{Li}_{2} \mathrm{MgSn}$ [41] shows that its lattice parameter $a$ is $0.676 \mathrm{~nm}$, belonging to the $F m \overline{3} m$ space group, with each unit cell containing $8 \mathrm{Li}$ atoms, $4 \mathrm{Mg}$ atoms and $4 \mathrm{Sn}$ atoms. Based on the atom positions in the unit cell and the structure factor of the planes, the atomic configurations of the $\{220\}_{L i_{2} M g S n}$ plane together with the close packed direction can be identified. As shown in Figure 5, there are four close packed or nearly close packed directions

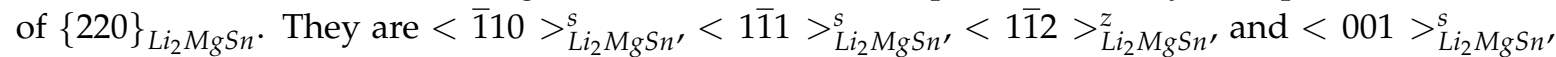
where the superscript " $S$ " denotes straight atom rows and " $Z$ " indicates the zigzag atom rows. Li is a simple BCC structure and there are three close packed or nearly close packed directions in the plane of $(110)_{\beta-L i}$. They are $<001>_{\beta-L i}^{s},<11 \overline{1}>_{\beta-L i}^{s}$ and $<\overline{1} 10>_{\beta-L i}^{s}$. According to the principle [39] that zigzag atom rows match with other zigzag rows and straight rows match with other straight rows, the $f_{r}$ values can be calculated [23]. There are three pairs $f_{r}$ value of matching directions below the critical value of $10 \%$, as shown in Table 2 . 


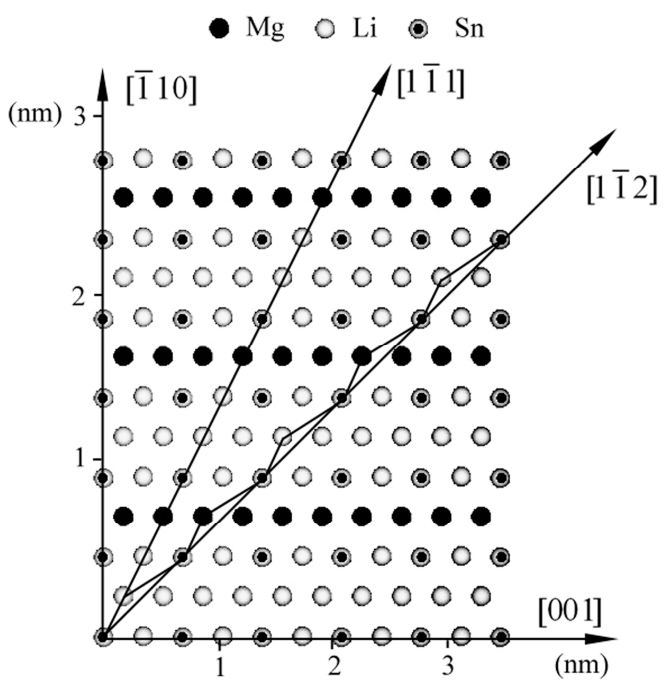

Figure 5. Atom configuration (220) ${ }_{L_{2} \mathrm{MgSn}}$ of $\mathrm{Li}_{2} \mathrm{MgSn}$ on plane at lattice parameter $a=0.676 \mathrm{~nm}$.

Table 2. Interatomic spacing misfit $\left(f_{r}\right)(\%)$ along the possible matching directions between the plane of $(220)_{L i_{2} M g S n}$ and $(110)_{\beta-L i}$.

\begin{tabular}{|c|c|c|c|c|c|}
\hline Direction Pairs & \multicolumn{5}{|c|}{ The Misfit (\%) between the Direction Pairs in $\mathrm{Li}_{2} \mathrm{MgSn}$ and $\mathrm{Li}$} \\
\hline No. $1-5$ & $\begin{array}{c}<1 \overline{11}>_{\beta-L i} / \\
<1 \overline{1} 0>_{L i_{2} M g S n} \\
57.38\end{array}$ & $\begin{array}{c}<1 \overline{11}>_{\beta-L \mathrm{i}} / \\
<1 \overline{1} 1>_{L i_{2} M g S n} \\
3.62\end{array}$ & $\begin{array}{c}<1 \overline{11}>_{\beta-L \mathrm{i}} / \\
<001>_{L i_{2} M g S n} \\
11.28\end{array}$ & $\begin{array}{c}<1 \overline{1} 0>_{\beta-L \mathrm{i}} / \\
<1 \overline{1} 0>_{L i_{2} M g S n} \\
3.62\end{array}$ & $\begin{array}{c}<1 \overline{1} 0>_{\beta-L i} / \\
<1 \overline{1} 1>_{L i_{2} M g S n} \\
40.98\end{array}$ \\
\hline No. 6-9 & $\begin{array}{c}<1 \overline{1} 0>_{\beta-L i} / \\
<001>_{L i_{2} M g S n} \\
31.85\end{array}$ & $\begin{array}{c}<001>_{\beta-L \mathrm{i}} / \\
<1 \overline{1} 0>_{L i_{2} M g S n} \\
\quad 36.53\end{array}$ & $\begin{array}{c}<001>_{\beta-L \mathrm{i}} / \\
<1 \overline{1} 1>_{L i_{2} M g S n} \\
16.53\end{array}$ & $\begin{array}{c}<001>_{\beta-L i} / \\
<001>_{L i_{2} M g S n} \\
3.62\end{array}$ & (2) \\
\hline
\end{tabular}

Hence, the crystallography matching relationship between $\mathrm{Li}$ and $\mathrm{Li}_{2} \mathrm{MgSn}$ can be predicted as: $<1 \overline{1} 0>_{\beta-L \mathrm{i}} / /<1 \overline{1} 0>_{L i_{2} M g S n},<001>_{\beta-L \mathrm{i}} / /<001>_{L i_{2} M g S n},<1 \overline{11}>_{\beta-L \mathrm{i}} / /<1 \overline{1} 1>_{L i_{2} M g S n}$, and $\{110\}_{\beta-L i} /\{220\}_{L i_{2} M g S n}$.

The calculated results implied that there was a good crystallographic matching relationship between $\mathrm{Li}_{2} \mathrm{MgSn}$ and the matrix. Therefore, compared to $\mathrm{LiMgAl}_{2}$ particles, $\mathrm{Li}_{2} \mathrm{MgSn}$ intermetallics had more potential to serve as the heterogeneous nucleation sites for the matrix in the DRX process, leading to an excellent grain refinement effect of the as-extruded LT142 alloy.

\section{Conclusions}

The as-cast and as-extruded LA141 (Mg-14Li-1Al) and LT142 (Mg-14Li-2Sn) alloys were prepared to investigate the effect of different alloying elements and intermetallics on the grain refinement in the $\mathrm{Mg}-14 \mathrm{Li}$ alloys. The corresponding results are summarized below.

(1) In the as-cast alloys, with $\mathrm{Al}$ or $\mathrm{Sn}$ addition to the $\mathrm{Mg}-14 \mathrm{Li}$ alloy, the grains of the as-cast $\mathrm{Mg}-14 \mathrm{Li}$ alloy were refined, and the grain size of the as-cast LA141 alloy was similar with that of LT142 alloy. The dominant driving force of grain refinement by $\mathrm{Al}$ or Sn in the as-cast Mg-14Li alloy was the solute effect of alloying elements.

(2) In the as-extruded alloys, the grains of the LT142 alloy with $\mathrm{Li}_{2} \mathrm{MgSn}$ particles were two times finer than those of the LA141 alloy with $\mathrm{LiMgAl}_{2}$. The better grain refinement impact of $\mathrm{Sn}$ in the as-extruded alloys can be attributed to the obvious heterogeneous nucleation effect of the $\mathrm{Li}_{2} \mathrm{MgSn}$ in the DRX process.

(3) The crystallographic orientation relationships between $\mathrm{LiMgAl}_{2} / \mathrm{Li}_{2} \mathrm{MgSn}$ and matrix were calculated applying edge-to-edge matching model. They were: $\mathrm{LiMgAl}_{2}$ did not match $\mathrm{Li}$ matrix, while $\mathrm{Li}_{2} \mathrm{MgSn}$ exhibited an excellent matching relationship with Li matrix as $\{110\}_{\beta-L \mathrm{i}} /\{220\}_{L_{2} \mathrm{MgSS}}$; 
$<1 \overline{1} 0>_{\beta-L \mathrm{i}} / /<1 \overline{1} 0>_{L i_{2} M g S n},<001>_{\beta-L \mathrm{i}} / /<001>_{L i_{2} M g S n},<\overline{111}>_{\beta-L \mathrm{i}} / /<1 \overline{1} 1>_{L i_{2} M g S n}$. Compared to $\mathrm{Al}, \mathrm{Sn}$ can be considered as a better grain refiner for $\beta$-Li based $\mathrm{Mg}$ alloys.

Acknowledgments: The authors gratefully acknowledge the Fundamental Research Funds for the Central Universities (2682016CX072), National Natural Science Foundation of China (51531002, 51171212, and 51474043) and The National Science and Technology Program of China (2013DFA71070 and 2013CB632200).

Author Contributions: Bin Jiang conceived and designed the experiment; Ying Zeng, Ruihong Li and Hengmei Yin performed the experiment; Ying Zeng and Ruihong Li analyzed the data; Ying Zeng wrote the paper; and Ying Zeng and Salih Al-Ezzi revised the paper.

Conflicts of Interest: The authors declare no conflict of interest.

\section{References}

1. Rao, G.S.; Prasad, Y. Grain boundary strengthening in strongly textured magnesium produced by hot rolling. Metall. Mater. Trans. A 1982, 13, 2219-2226. [CrossRef]

2. Wang, J.; Zhang, X.; Lu, X.; Yang, Y.; Wang, Z. Microstructure, texture and mechanical properties of hot-rolled Mg-4Al-2Sn-0.5Y-0.4Nd alloy. J. Magnes. Alloy 2016, 4, 207-213. [CrossRef]

3. Chen, Z.H. Wrought Magnesium Alloy, 1st ed.; Chemical Industry Press: Beijing, China, 2005; pp. 48-57.

4. Moser, Z.; Zakulski, W.; Schwitzgebel, G. Thermodynamic studies and the phase diagram of the Li-Mg system. Metall. Mater. Trans. A 1996, 30, 1120-1128.

5. Zou, Y.; Zhang, L.; Wang, H.; Tong, X.; Zhang, M.; Zhang, Z. Texture evolution and their effects on the mechanical properties of duplex Mg-Li alloy. J. Alloy. Compd. 2016, 669, 72-78. [CrossRef]

6. Counts, W.A.; Friák, M.; Raabe, D.; Neugebauer, J. Using ab initio calculations in designing bcc Mg-Li alloys for ultra-lightweight applications. Acta Mater. 2009, 57, 69-76. [CrossRef]

7. Liu, B.; Zhang, J.H.; Niu, Z.Y.; Li, J.Q. Effect of La-Rich Misch Metal on Microstructure and Mechanical Properties of As-Extruded Mg-14Li-3Al Alloy. Adv. Mater. Res. 2012, 391, 32-36. [CrossRef]

8. Yoshida, Y.; Cisar, L.; Kamado, S.; Kojima, Y. Low temperature superplasticity of ECAE processed Mg-10\% Li-1\% Zn alloy. Mater. Trans. 2002, 43, 2419-2423. [CrossRef]

9. Mordike, B.L.; Ebert, T. Magnesium: Properties-Applications-Potential. Mater. Sci. Eng. A 2001, 302, 37-45. [CrossRef]

10. Jackson, J.; Frost, P.; Loonam, A.C.; Eastwood, L.; Lorig, C. Magnesium-lithium base alloys preparation, fabrication, and general characteristics. Trans. AIME 1949, 185, 149-168.

11. Yang, Y.; Peng, X.; Ren, F.; Wen, H.; Su, J.; Xie, W. Constitutive Modeling and Hot Deformation Behavior of Duplex Structured Mg-Li-Al-Sr Alloy. J. Mater. Sci. Technol. 2016, 32, 1289-1296. [CrossRef]

12. Xu, T.; Peng, X.; Jiang, J.; Xie, W.; Chen, Y.; Zhang, X. Comparative study on the microstructure and mechanical properties of $\mathrm{Mg}-\mathrm{Li}-\mathrm{Al}$ based alloys with yttrium and strontium addition. J. Wuhan Univ. Technol. Mater. Sci. Ed. 2015, 30, 626-630. [CrossRef]

13. Kim, J.T.; Park, G.H.; Kim, Y.S.; Hong, S.H.; Park, H.J.; Suh, J.Y.; Son, H.T.; Lee, M.-H.; Park, J.M.; Kim, K.B. Effect of $\mathrm{Ca}$ addition on the plastic deformation behavior of extruded $\mathrm{Mg}-11 \mathrm{Li}-3 \mathrm{Al}-1 \mathrm{Sn}-0.4 \mathrm{Mn}$ alloy. J. Alloy. Compd. 2016, 687, 821-826. [CrossRef]

14. Hansen, F.; Eschurmann, G.F. The deformation and strengthening mechanisms of the multiphase $\mathrm{Mg}-\mathrm{Li}-\mathrm{A} 1$ alloys. Metals 1986, 40,1-6.

15. Jiang, B.; Liu, Y.; Li, R.; Xiang, Q.; Zeng, Y.; Pan, F. Effects of Yttrium and Strontium Addition on Electrochemical Behavior of Mg-14Li-1Al Alloys. Rare Metal Mater. Eng. 2013, 42, 1999-2003.

16. Morishige, T.; Ueno, K.; Okano, M. Effect of Impurity Fe Concentration on the Corrosion Behavior of Mg-14 mass\% Li-1 mass\% Al Alloy. Mater. Trans. 2014, 55, 1506-1509. [CrossRef]

17. Liu, T.; Zhang, W.; Wu, S.D.; Jiang, C.B.; Li, S.X.; Xu, Y.B. Mechanical properties of a two-phase alloy Mg-8\%Li-1\%Al processed by equal channel angular pressing. Mater. Sci. Eng. A 2003, 360, 345-349. [CrossRef]

18. Jiang, J.; Bi, G.; Wang, G.; Jiang, Q.; Lian, J.; Jiang, Z. Strain-hardening and warm deformation behaviors of extruded Mg-Sn-Yb alloy sheet. J. Magnes. Alloy. 2014, 2, 116-123. [CrossRef]

19. Sasaki, T.T.; Elsayed, F.R.; Nakata, T.; Ohkubo, T.; Kamado, S.; Hono, K. Strong and ductile heat-treatable Mg-Sn-Zn-Al wrought alloys. Acta Mater. 2015, 99, 176-186. [CrossRef] 
20. Kim, B.; Lee, J.G.; Park, S.S. Superplasticity and load relaxation behavior of extruded Mg-8Sn-3Al-1Zn alloy at $250^{\circ}$ C. Mater. Sci. Eng. A 2016, 656, 234-240. [CrossRef]

21. Lv, B.; Peng, J.; Peng, Y.; Tang, A. The effect of addition of $\mathrm{Nd}$ and Ce on the microstructure and mechanical properties of ZM21 Mg alloy. J. Magnes. Alloy 2013, 1, 94-100. [CrossRef]

22. Jiang, B.; Yin, H.M.; Yang, Q.S.; Li, R.H.; Pan, F.S. Effect of stannum addition on microstructure of as-cast and as-extruded Mg-5Li alloys. Trans. Nonferr. Metal Soc. China 2011, 21, 2378-2383. [CrossRef]

23. Zeng, Y.; Jiang, B.; Zhang, M.X.; Yin, H.M.; Li, R.H.; Pan, F.S. Effect of $\mathrm{Mg}_{24} \mathrm{Y}_{5}$ intermetallic particles on grain refinement of Mg-9Li alloy. Intermetallics 2014, 45, 18-23. [CrossRef]

24. Yi, Q.X. Study on the preparation technology, microstructure, and mechanical property of Mg-14Li-X alloys. Master's Thesis, Hunan University, Hunan, China, 2007.

25. Лякишев, Н.П. Metal Binary System Phase Diagrams Handbook; Guo, Q.W., Ed.; Chemical Industry Press: Beijing, China, 2009; p. 875.

26. Wang, J.F.; Dan-Dan, X.U.; Ruo-Peng, L.U.; Pan, F.S. Damping properties of as-cast Mg- $x \mathrm{Li}-1 \mathrm{Al}$ alloys with different phase composition. Trans. Nonferr. Metals Soc. China 2014, 24, 334-338. [CrossRef]

27. Straumal, B.B.; Baretzky, B.; Kogtenkova, O.A.; Straumal, A.B.; Sidorenko, A.S. Wetting of grain boundaries in $\mathrm{Al}$ by the solid $\mathrm{Al}_{3} \mathrm{Mg}_{2}$ phase. J. Mater. Sci. 2009, 45, 2057-2061. [CrossRef]

28. Protasova, S.G.; Kogtenkova, O.A.; Straumal, B.B.; Zięba, P.; Baretzky, B. Inversed solid-phase grain boundary wetting in the Al-Zn system. J. Mater. Sci. 2011, 46, 4349-4353. [CrossRef]

29. Easton, M.; Stjohn, D. Grain refinement of aluminum alloys: Part I. the nucleant and solute paradigms-A review of the literature. Metall. Mater. Trans. A 1999, 30, 1613-1623. [CrossRef]

30. Easton, M.; StJohn, D. Grain refinement of aluminum alloys: Part II. Confirmation of, and a mechanism for, the solute paradigm. Metall. Mater. Trans. A 1999, 30, 1625-1633. [CrossRef]

31. Fu, H.M.; Qiu, D.; Zhang, M.X.; Wang, H.; Kelly, P.M.; Taylor, J.A. The development of a new grain refiner for magnesium alloys using the edge-to-edge model. J. Alloy. Compd. 2008, 456, 390-394. [CrossRef]

32. Greer, A.L.; Bunn, A.M.; Tronche, A.; Evans, P.V.; Bristow, D.J. Modelling of inoculation of metallic melts: Application to grain refinement of aluminium by Al-Ti-B. Acta Mater. 2000, 48, 2823-2835. [CrossRef]

33. Greer, A.L.; Cooper, P.S.; Meredith, M.W.; Schneider, W.; Schumacher, P.; Spittle, J.A.; Tronche, A. Grain Refinement of Aluminium Alloys by Inoculation. Adv. Eng. Mater. 2003, 5, 81-91. [CrossRef]

34. Kaibyshev, R. 5-Dynamic recrystallization in magnesium alloys. In Advances in Wrought Magnesium Alloys; Bettles, C., Ed.; Woodhead Publishing: Cambridge, UK, 2012; pp. 186-225.

35. Humphreys, F.; Kalu, P. Dislocation-particle interactions during high temperature deformation of two-phase aluminium alloys. Acta Metall. 1987, 35, 2815-2829. [CrossRef]

36. McQueen, H. Development of dynamic recrystallization theory. Mater. Sci. Eng. A 2004, 387, $203-208$. [CrossRef]

37. Zhang, M.X.; Kelly, P.M. Edge-to-edge matching and its applications: Part I. Application to the simple HCP /BCC system. Acta Mater. 2005, 53, 1073-1084. [CrossRef]

38. Liu, Z.; Qiu, D.; Wang, F.; Taylor, J.A.; Zhang, M. The grain refining mechanism of cast zinc through silver inoculation. Acta Mater. 2014, 79, 315-326. [CrossRef]

39. Qiu, D.; Zhang, M.; Kelly, P.; Furuhara, T. Discovery of plate-shaped athermal $\omega$ phase forming pairs with $\alpha^{\prime}$ martensite in a Ti-5.26 wt. \% Cr Alloy. Scr. Mater. 2013, 69, 752-755. [CrossRef]

40. PCPDFWIN v.2.3, JCPDS Card Nos. 08-0283; International Center for Diffraction Data: Newtown Square, PA, USA, 2002.

41. Pauly, H.; Weiss, A.; Witte, H. Face Centred Cubic Alloys of Composition $\mathrm{Li}_{2} \mathrm{MgX}$ with Body-Centred Substructure. Z. Metallkd 1968, 59, 414-418.

(C) 2017 by the authors. Licensee MDPI, Basel, Switzerland. This article is an open access article distributed under the terms and conditions of the Creative Commons Attribution (CC BY) license (http:/ / creativecommons.org/licenses/by/4.0/). 